\title{
Attitudes Toward Technologies of the Near Future: The Role of Technology Readiness in a Hungarian Adult Sample
}

\author{
Sára Imola Csuka* \\ Károly Rácz School of PhD Studies \\ Semmelweis University, Budapest, Hungary \\ saciimola@gmail.com \\ Tamás Martos \\ Department of Personality, Clinical and Health Psychology \\ University of Szeged, Hungary \\ Mihály Kapornaky \\ Department of Social Psychology \\ Eötvös Loránd University, Hungary \\ Viola Sallay \\ Department of Personality, Clinical and Health Psychology \\ University of Szeged, Hungary \\ Christopher Alan Lewis \\ Department of Psychology \\ Leeds Trinity University, United Kingdom
}

Received 2 September 2018

Accepted 14 June 2019

Published 8 August 2019

\begin{abstract}
Past decades' rapid development of technological innovations can ease individual's everyday lives, but they can also convey a sense of frustration. The aim of the present study was to investigate attitudes toward technologies that are expected to become widespread in the near future. The Technology Readiness Index was administered to a sample of Hungarian respondents to measure the capacity to adopt technologies. The results add significant novelties about the specific patterns related to perceptions of considerably different future technologies, emphasizing the unique role of optimism. Derivations are further specified by demographic characteristics, future directions and practical implications are also discussed.
\end{abstract}

Keywords: Technology Readiness Index (TRI); autonomous car; telemedicine; enhanced living environments; socio-economic features.

\section{Introduction}

During the past decades, a rapid and remarkable development of technology has been observed (e.g.: 3D printing revolution, autonomous transportation, surgical and

*Corresponding author. 
humanoid robots) and this can have farreaching consequences for economic systems, healthcare and transportation, and consequentially it can reshape everyday life [Kwon et al. (2017); Mesko (2015); Meskó et al. (2017)]. According to Webcache's [2017] statement about the trends of technology use behavior in 2017, more than half of the world's population utilizes the Internet (which means $80 \%$ growth during the past five years) and three quarters of the population own mobile phones. Nonetheless, due to Internet coverage, the range of technology-based services and applications is almost infinite. Accordingly, there are under development smart tyres [Zhang et al. (2013)], smart wheelchairs [Huang et al. (2017)], wearable devices, which measure biological functions and are interconnected with intelligent vehicles [Sun et al. (2017)], or smart watches designed for measurement of biological data and can enable the user to avoid possible medical emergencies [Do et al. (2016)]. Studies examining technological development mainly focus on "hard" data (such as a country's index of internet coverage) while disregarding human aspects [Rojas-Méndez et al. (2017)].

Simultaneously, consumers' judgements about these technological solutions are less clear as technology also conveys a sense of disappointment and frustration [Kerschner and Ehlers (2016)]. In an early longitudinal study of the field, Mick and Fournier [1998] defined eight paradoxes, which they identified with qualitative methods. Accordingly, people have to deal with the contradictions of technology, specifically control and chaos, freedom and enslavement, new and obsolete, competence and incompetence, efficiency and inefficiency, fulfilling and creating needs, assimilation and isolation and engaging and disengaging.

\subsection{Purpose, research questions}

Despite the spread of technological innovations, so far little is known about consumer's predispositions. Moreover, attitudes toward technologies may differ depending on the population's characteristics (such as socioeconomic status, previous experiences with technology) and the type of technology itself [Yol et al. (2006); Rojas-Méndez and Parasuraman (2015); Øyen et al. (2017)]. Although readiness for technology has been studied across different cultures [Martos et al. (2018); RojasMéndez et al. (2017)], this study adds to the current literature which is the first to examine attitudes toward upcoming technological solutions in a Hungarian adult sample. As the technological market is highly interconnected through countries, it is recommended for vendors from various places in the world to be aware of the prospective reception of their product or service. It is assumed that the results of the present study will prove to be beneficial not only for researchers, but for vendors and users of technology as well. For suppliers, it is profitable if their product is useful and easily saleable and consumers can also take advantage of that if the technology, which they inevitably come across, is customized [Smith et al. (2018)] and meets their expectations. The paper comprises the forthcoming points. Section 1.2 discusses the previous literature on the TR construct, and other factors which can have an influence on the levels of TR are discussed in Sec. 1.3, then three technological solutions are presented in Sec. 1.4. Section 1.5 formulates the aim of the study and hypotheses. Section 2 discusses the methodology and results of the study. 
In Secs. 3.1-3.3, results, Sec. 3.4, limitations and Sec. 3.5, possible future directions of the research are discussed.

\subsection{Technology readiness}

For the evaluation of technology use behavior, Parasuraman [2000] coined the term "technology readiness" which refers to people's propensity to embrace and use new technologies for accomplishing goals in their home life and at work [Parasuraman (2000), p. 308]. Technology readiness can be considered as a general attitude, a predisposition which consists of several driving and inhibiting factors. Optimism means positive attitudes toward technology, accordingly the person conceives that technology provides greater control, flexibility and effectivity. The other enabling dimension is innovativeness which refers to openness to new technologies. On the other hand, discomfort, overwhelmed and lack of sense of control, and insecurity, scepticism about technology itself and its appropriate operation, work as inhibiting factors of technology readiness. To capture this construct, the Technology Readiness Index (TRI) was developed by Parasuraman [2000] in which items are formulated generally so that the questionnaire can be easily applied for distinct, and even for future, technologies. Respectively we can make evaluations of actual and future utilization of these technologies based on TRI.

Technology readiness as a construct, or some components of it, and the relationships with usage behavior has been studied in several countries. Such research has mainly focused on specific services or technologies [Chen and Lin (2018); Smith et al. (2018)]. For example, innovativeness positively predicted the social commerce behavior of Korean college students, especially to the extent they perceive this information communication technology useful, easily usable and controllable [Joo (2015)]. In their Chilean-based research, Rojas-Méndez and Parasuraman [2015] investigated a wider range of technological solutions, for instance, diagnosing and treating medical problems via the Internet, shopping online or voting on parliamentary elections. Factors of the TRI predicted consumer behavior when an economic or physical risk came into view. The components of the TRI, with optimism being the strongest, predicted the attitudes toward certain software used by employees of a Belgian financial enterprise [Wahlster et al. (2015)]. In addition, TRI anticipated judgements and adaptation to several technology-based services on the sample of Greek college students [Roumeliotis and Maria (2014)]. According to a study conducted in the United Kingdom [Ramtohul (2015)], from high-levels of technology readiness, solid predictions can be made for the usage of technological services (e.g. online shopping, having internet access, using a computer or cellular phone, drawing on E-health services). In a recent study conducted in Chile and the USA [Rojas-Méndez et al. (2017); Martens et al. (2017)], evidence indicated that technology readiness is a reliable predictor of technological attitudes and also behavioral intentions in significantly different cultures.

\subsection{Other factors determining technological readiness}

Beyond predispositions measured by the TRI [Parasuraman (2000)], socio-economic factors also have an influence on technology adaptation [Gajanayake et al. (2016)]. 
Although technological solutions have become more and more widespread, these are not accessible for everyone [Kapiriri (2015); Rojas-Méndez and Parasuraman (2015)]. Presumably, that is why people with lower education levels and lower income are less ready to embrace new technological achievements [Magotra et al. (2015); Rojas-Méndez et al. (2017)]. There may be economic reasons for this, or perhaps those with higher education levels consider themselves more competent when coming across new technology [Magotra et al. (2015)].

Research findings concerning sex differences are fairly inconsistent, although based on the meta-analysis of Cai et al. [2017] incorporating scientific results from 1997 to 2014 it can be concluded that males overall hold more favorable perceptions about new technologies. A considerable amount of research has provided evidence that women are less open to new technologies [Rojas-Méndez et al. (2017); RojasMéndez and Parasuraman (2015); Zhou et al. (2007)] perhaps because of basic differences in fields of interest [Billington et al. (2007)] or that women base their judgements on other aspects [Wang et al. (2009); Riquelme and Rios (2010); Venkatesh and Morris (2000)]. So, they consider these innovations less socially useful [Cai et al. (2017)], experience higher levels of anxiety [Venkatesh and Morris (2000)] and lower levels of self-efficacy [Cai et al. (2017)].

In addition, as different age groups hold different concepts and behave in a different way, there are differences between age groups in judgements and usage behavior of technological innovations [Magotra et al. (2015); Rojas-Méndez and Parasuraman (2015); Yol et al. (2006)]. Previous research has revealed that elderly people are less optimistic about high-tech inventions that are put on the market [Øyen et al. (2017); Rojas-Méndez et al. (2017)]. It can be assumed that these differences are due to lack of their digital literacy [Øyen et al. (2017)], their lower selfconfidence and mastery when using these products and that they shift their belief system much slower [Magotra et al. (2015)], but not the lack of skills and accessibility of the technological services [Siren and Knudsen (2017)]. These socio-economic differences were captured by Tsikriktsis [2004] who identified four clusters in the United Kingdom based on the TRI factors. The groups differed in demographic features. "Laggards" (who focus on the downside of technology) are mainly women, older than 45 years with lower income and education level. "Skeptics" (who are not too optimistic about new technologies, but at the same time not afraid of them) are mostly males, younger than 45 years old with medium or higher levels of education. "Explorers" (who are expressly optimists and innovatives) usually males at the end of their 20s or 30s with higher income and high levels of education. "Pioneers" (who are optimists and innovatives, but experience discomfort and insecurity as well) are mainly women, older than 35 years with lower levels of education and with average income [Tsikriktsis (2004)].

\subsection{Technologies of the near future}

According to the predictions of eNet [2017], initial 5G solutions may appear by 2020, which means far faster data traffic in proportion to $4 \mathrm{G}$ in 2018-2019 and this can 
open the gate to intelligent vehicular systems, intelligent cities and homes and even cross-border robotic surgeries. These high-tech solutions have not been widely used, but are apparently becoming more and more wide-spread, hence it is crucial to reveal potential user's suppositions about these.

In this study, three broadly defined technological innovations served as objects of attitudes. The aim was to capture perceptions of future technologies which were considerably different in nature. These were the following: Autonomous or Self-driving Car (AC), Enhanced Living Environments (ELE) and Telemedicine (TM). An AC [Marçal et al. (2017)] is able to get about autonomously in traffic, but the driver can take over the control of it if it is required by the situation. ELE [Dobre et al. (2016)] can be useful for the elderly or persons with reduced mobility or disability as it monitors the position and the state of people inhabiting the house, thereby supporting independent living. Lastly, TM [Glinkowski (2006)] is a healthcare service through which diagnosing or curing happens by long-distance surveillance, hence the patient and the healthcare provider don't meet physically.

These afore-mentioned achievements have several advantages. For instance, using ACs would ease transportation, help to foresee traffic jams and avoid road accidents [Swan (2015)]. Health IT Systems under the umbrella of ELE and TM can be upgraded [Mrosek et al. (2015)] could reduce inequalities shown in the accessibility of healthcare services, which often originate from the lack of availability of healthcare professionals [Kapiriri (2015); Krishna et al. (2016)]. By identifying health problems more rapidly this can help patients get medical assistance faster [Al Dahdah et al. (2015)], can enhance adherence to medical treatment [Mrosek et al. (2015)], and can serve as a bridging solution for those who feel anxiety from visiting the doctor [Ramtohul (2015)].

At the same time, these technological solutions also hold some risks and challenges. There are ethical dilemmas such as the matter of data security, or retractability [Gajanayake et al. (2016); Swan (2015)] and integrating the incoming and heterogenous data formats for easier handling [Batra et al. (2015); Kliem et al. (2016); Larburu et al. (2016)]. A potential objection can be the lack of doctorpatient communication in the course of healing which is well known to be fundamental for recovery [Ramtohul (2015)] and that increased autonomy of sick people can bring along abuse and misusage of technology [Kapiriri (2015)]. As these services would be made available via infocommunitaion devices, this could deepen the gap shown in accessibility [Wahlster et al. (2015)]. Again, patients' willingness to share their medical information [Ivanov et al. (2015)] and the time needed to adopt these innovations [Swan (2015); Ramtohul (2015)] can be problematic, moreover, to what extent the financial concerns of the provider are involved should be taken into account [Al Dahdah et al. (2015)].

Such innovations have not been accessible in everyday life yet, but under intensive development may become widespread (in Hungary) [e.g. Danis et al. (2016); Király and MAIN Csoport (2010); Orbók (2015)]. Consequently, examining the attitudes of future consumers toward these technologies is of high priority. 


\section{S. I. Csuka et al.}

\subsection{The present study}

Previous studies have mainly focused on attitudes toward special technological solutions, which affected only a limited circle of consumers [e.g. Rojas-Méndez and Parasuraman (2015); Roumeliotis and Maria (2014); Walczuch et al. (2007); Smith et al. (2018)]. The most important objective of the present study is to give a comprehensive view about attitudes toward three upcoming and broadly defined technological devices (which differ significantly from each other in nature) and overall levels of technology readiness in a Hungarian adult sample.

Optimism and innovation serve as drivers, while discomfort and insecurity serve as inhibitors of the technology readiness [Parasuraman (2000)]. Several studies have demonstrated that factors of technology readiness have relationship with ratings of different kinds of technological solutions [Ramtohul (2015); Walczuch et al. (2007)].

Accordingly, it was hypothesized that:

H1: Optimism and innovativeness predicts positively the attitudes toward the three future technologies.

$\mathrm{H} 2$ : Discomfort and insecurity predicts negatively the attitudes toward the three future technologies.

There is strong evidence that there is heterogeneity of appraisals of a technology among people living in the same country but who differ in their demographic characteristics [Rojas-Méndez and Parasuraman (2015); Tsikriktsis (2004)].

Accordingly, it was hypothesized that:

H3: Sociodemographic status is interrelated with attitudes toward the three future technologies, specifically:

According to previous literature males show higher levels of openness for technology as having lower levels of anxiety and higher levels of self-efficacy [Cai et al. (2017); Venkatesh and Morris (2000)].

(a) Males hold more positive attitudes toward technology than females.

Younger individuals change their mindsets more flexibly and their social environment has a stronger influence on them and they also have higher levels of e-literacy [Rojas-Méndez and Parasuraman (2015); Øyen et al. (2017)].

(b) Younger age group (18-29) hold more positive attitudes toward technology than older (30-39 and 40-50) age groups.

\section{Methods}

\subsection{Sample}

For data collection, non-equal probability of selection methods, i.e. convenience sampling and snowball method were used. The aim was to have male-female ratio to be approximately balanced, but to have heterogeneity of the sample with regards to age and occupation. 


\subsection{Procedure and data collection}

The study was conducted as a part of an extensive research project into technological attitudes organized by the Institute of Psychology of Szeged University. Data collection took place between February and August 2017 and the final results are based on the responses of 333 participants who were requested to complete an online survey (Google forms). The study was designed with due regard to the related ethical laws and was run with the required permissions (Common Ethical Review Board of the Hungarian Institutes of Psychology). Participation was voluntary, anonymous and respondents were given sufficient guidance about the main aims of the research and about confidentail data management after which they signed an informed consent form and began the online survey which took about $15 \mathrm{~min}$.

\subsection{Instruments}

\subsubsection{Demographic questions}

The first section of the test battery focused on demographic questions such as gender, age, level of education and occupation.

\subsubsection{Attitudes toward three concrete technological solutions}

AC, ELE and TM were tested as attitude objects. Respondents were given short descriptions about these technologies and then they were asked to evaluate them according to three questions: (1) the desirability of bringing these products into general use; (2) the probability of choosing these technological solutions for themselves; (3) the probability of choosing these technological solutions for the elderly or needy (e.g. disabled) relatives. Evaluation of these aspects occurred on a 10-point Likert-type scale $(1=$ not desirable/probable at all, $10=$ completely desirable/ probable).

Scores of the evaluations with respect to the three aspects (i.e. general usefulness, probability of personal choice or choice for a relative) were averaged in case of each technology. These average scores were considered the indices of the attitudes toward the technological solutions.

\subsubsection{Technology Readiness Index [Parasuraman (2000)]}

The TRI measures the capacity of respondents to learn and adopt technologies. The questionnaire consists of 36 items and is divided into four subscales; optimism (e.g. "technology makes you more efficient in your occupation"), innovativeness (e.g. "you keep up with the latest technological developments in your areas of interest"), discomfort (e.g. "there is no such thing as a manual for a high-tech product or service that is written in plain language") and insecurity (e.g. "the human touch is very important when doing business with a company"). The two former serve as a driver and the latters are inhibiting dimensions. Participants evaluated the statements on a 7 -point Likert-type scale $(1=$ strongly disagree, $7=$ strongly agree $)$. As the TRI did not have a Hungarian version, at the starting point of the research it 
was translated into Hungarian correspondently to the guidelines of WHO [2017] and validated in a Hungarian adult sample [Marcal et al. (2019)]. Since the validation process resulted in an alternative factor structure of the scale with shorter subscales [cf. Martos et al. (2019), in the present study we used 11 items of the original TRI (Appendix A). To increase the potential fit of the model in SEM, we retained items with a factor loading above 0.4 from the original version. This solution was assumed to preserve the four dimensions of the original TRI model, and thus, it was included in the following analyses.

\subsection{Statistical methods}

Statistical analyses were conducted with IBM SPSS Statistics 22. Descriptive statistics were run and Cronbach alpha values were calculated. For hypothesis testing Pearson Product Moment Correlation and, for a more precise examination of the relations between the studied constructs, Structural equation modeling was used with the 30 days trial software of IBM SPSS Amos 24.

\subsection{Results}

\subsubsection{Descriptive statistics of the sample}

Respondents with uncompleted questionnaires were excluded from the study and finally we achieved a sample of 212 women and 121 men, their ages ranged from 19 to 77 years $(\mathrm{SD}=14.04 ; M=38.61 ; \mathrm{SE}=0.77)$. For further analysis three age groups were generated; from 18 to 29 years (31\% of the participants), from 30 to 39 years (27\% of the participants) and from 40 to 50 years ( $42 \%$ of the participants). Most of the respondents had higher level education $(74.5 \%)$ or medium/secondary education $(24.01 \%)$ and only $1.5 \%$ of them had primary education. More than half of the participants $(54.3 \%)$ were white-collar workers (e.g. teacher or office worker). Most respondents rated their health status good or very good $(79.3 \%)$. According to the TRI, most of the respondents tend to hold positive attitudes towards technology (optimism: $M=5.13, \mathrm{SD}=1.07$; innovativeness: $M=4.22, \mathrm{SD}=1.47$; discomfort: $M=3.32, \mathrm{SD}=1.53$; insecurity $=3.97, \mathrm{SD}=1.11)$.

\subsubsection{Hypothesis testing}

Pearson-correlation coefficients corresponded to our hypotheses (Table 1). Facilitating factors of the TRI were positively related to better evaluations of each

Table 1. Pearson-correlation (one-tailed) ${ }^{* *} p<0.01$.

\begin{tabular}{|c|c|c|c|c|c|c|c|}
\hline & 1 & 2 & 3 & 4 & 5 & 6 & 7 \\
\hline 1. TRI optimism & - & & & & & & \\
\hline 2. TRI innovativeness & $0.464^{* *}$ & - & & & & & \\
\hline 3. TRI discomfort & $-0.120 *$ & $-0.097 *$ & - & & & & \\
\hline 4. TRI insecurity & $-0.246 * *$ & $-0.223 * *$ & $0.258^{* *}$ & - & & & \\
\hline 5. AC attitudes & $0.365^{* *}$ & $0.320 * *$ & $-0.171 * *$ & $-0.178 * *$ & - & & \\
\hline 6. ELE attitudes & $0.304^{* *}$ & $0.181^{* *}$ & $-0.083 * *$ & $-0.190 * *$ & $0.495^{* *}$ & - & \\
\hline 7. TM attitudes & $0.424^{* *}$ & $0.264^{* *}$ & -0.070 & $-0.198 * *$ & $0.439 * *$ & $0.410^{* *}$ & - \\
\hline
\end{tabular}


technological solution, while inhibiting factors were negatively related to them. Among the TRI subscales, optimism had the strongest associations with the outcome evaluation indices.

In order to further examine these correlations in a multivariate way a Structural Equation Model was built to portray the complex relationships of a justified theoretical model [Schreiber et al. (2006)]. The first general model comprises all of the hypothesized relationships between the studied constructs (Fig. 1).

According to the Chi-square statistics $\left(\chi^{2}=321.08, d f=149, p<0.001\right)$ the model had a valid absolute model fit as the probability value is less than 0.05 . The Comparative Fix Index (CFI) value $=0.95$ shows acceptable model fit as reaching the criteria of 0.95 indicating good fit. Other goodness-of-fit indicators, Normed Fit Index $(\mathrm{NFI})=0.91$, Incremental Fit Indices (IFI) $=0.95$ and Tucker Lewis Index $(\mathrm{TLI})=0.94$, are also close to 0.95 which indicates a good model fit. Parsimony adjusted fit indicator Root Mean Square Error Approximated (RMSEA) $=0.06$, which should be less than 0.05 to be regarded as acceptable. The content validity of the model was based on the theoretical framework and items adopted from the study of Parasuraman [2000], although only a proportion of the items were retained. The construct validity indices of the measurement model are shown in Table 2. The Capability Ratio (CR) values are above 0.7 for all of the constructs except

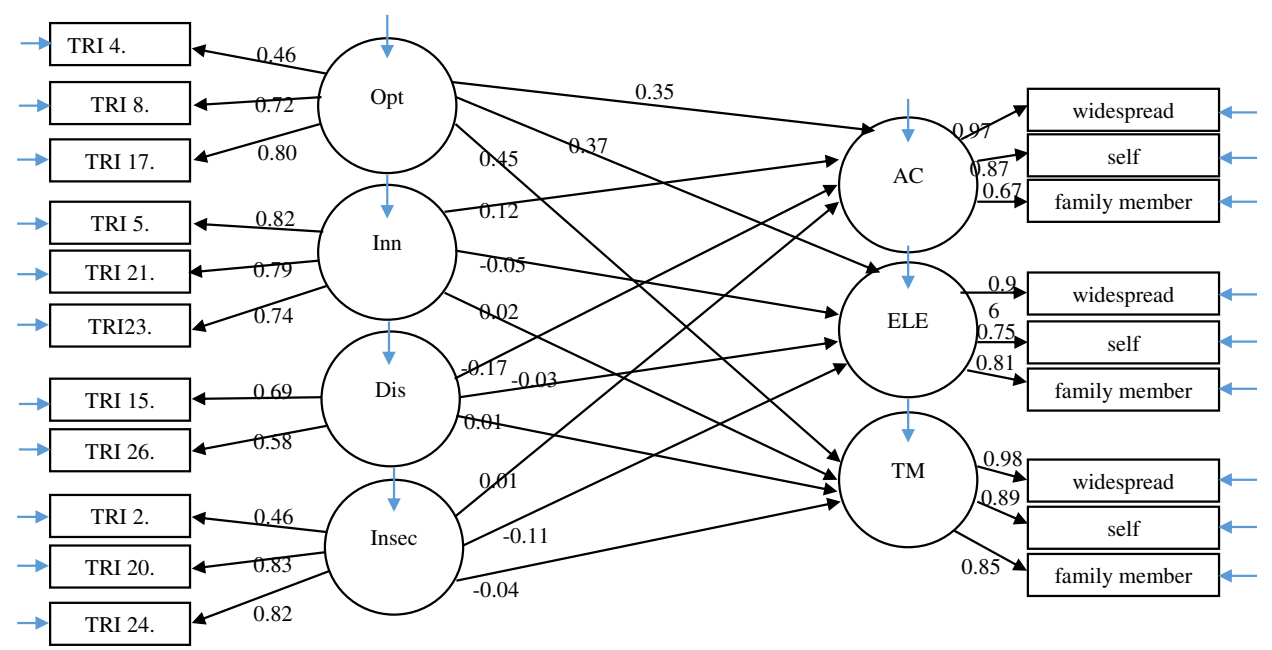

Fig. 1. Structural equation modeling — Path diagram of the studied construct.

Table 2. Construct validity indices of the TRI factors.

\begin{tabular}{lcccc}
\hline & CR & AVE & MSV $(\leftrightarrow=$ correlation between the two constructs $)$ & ASV $=0.125$ \\
\hline TRI optimism & 0.706 & 0.456 & TRI optimism $\leftrightarrow$ TRI innovativeness \\
TRI innovativeness & 0.829 & 0.618 & TRI discomfort $\leftrightarrow$ TRI innovativeness \\
TRI discomfort & 0.575 & 0.405 & TRI insecurity $\leftrightarrow$ TRI discomfort \\
TRI insecurity & 0.760 & 0.527 & TRI insecurity $\leftrightarrow$ TRI innovativeness \\
& & & TRI optimism $\leftrightarrow$ TRI discomfort \\
& & TRI insecurity $\leftrightarrow$ TRI optimism \\
\hline
\end{tabular}




\section{S. I. Csuka et al.}

discomfort and some of the Average Variance Extracted (AVE) values of the TRI (optimism and discomfort) are under the criteria of 0.05 , showing a weaker convergent validity, but $C R$ values are higher than the AVE values in each of the constructs.

As AVE values are above the Maximum Shared Variance (MSV) values and the AVE values are higher than the ASV, it indicates a good discriminant validity of the construct.

As shown in Table 3, among the TRI factors optimism had a significant impact on all of the attitude objects; AC $(p<0.001)$, ELE $(p<0.001)$ and TM $(p<0.001)$ and discomfort also accounted for significant amount of the variance of $\mathrm{AC}(p=0.04)$.

Additionally, we examined differences between the means of unobserved variables with regard to gender and age using Multiple-Group Analysis. First, the TRI factors were examined along these aspects. A model was built on the four TRI factors and as it resulted an acceptable model fit $\left(\chi^{2}=62.06, d f=38, p=0.008, \chi^{2} / d f=1.63\right.$, CFI $0.97, \mathrm{NFI}=0.94, \mathrm{IFI}=0.97, \mathrm{TLI}=0.97$ and $\mathrm{RMSEA}=0.04)$ further investigation of gender and age differences were undertaken. When sex was put into the analysis of the TRI factors Chi-square test showed significant difference between the generated and the saturated models $\left(\Delta \chi^{2}=43.798, \Delta d f=4\right)$ indicating difference between intercepts and regression weights between the models. The model examining age also proved to be different from the saturated models $\left(\Delta \chi^{2}=12.81, \Delta d f=4\right)$. Model comparisons show that technology readiness varies across groups (i.e. gender: $\left(\chi^{2}=43.78, d f=4, p<0.001\right.$ and age: $\left.\chi^{2}=12.1, d f=4, p=0.012\right)$. According to the Multiple-Group Analysis, females compared to male respondents are less innovative $(p<0.001)$, more insecure $(p=0.005)$ and less optimistic $(p=0.016)$ about new technologies. Younger respondents have lower levels of insecurity $(p=0.001)$ and hold all in all favorable attitudes toward technology, although these differences did not reach the level of significance (Table 4).

In the next step, the three attitude objects regarding gender and age differences were examined further. First, a model was built on the three technological solutions (AC, ELE and TM, respectively). Each latent variable of AC, ELE and TM was assumed to be defined by three measured variables (general usefulness, probability of

Table 3. Results of hypotheses.

\begin{tabular}{lrrrr}
\hline & Std Beta & SE & CR & \multicolumn{1}{c}{$P$} \\
\hline Optimism $\rightarrow$ AC & 1.437 & 0.399 & 3.601 & $p<0.001$ \\
Innovativity $\rightarrow$ AC & 0.237 & 0.163 & 1.456 & 0.145 \\
Innovativity $\rightarrow$ ELE & -0.074 & 0.123 & -0.604 & 0.546 \\
Innovativity $\rightarrow$ TM & 0.031 & 0.158 & 0.198 & 0.843 \\
Discomfort $\rightarrow$ TM & -0.006 & 0.176 & -0.037 & 0.971 \\
Discomfort $\rightarrow$ ELE & -0.052 & 0.138 & -0.381 & 0.704 \\
Discomfort $\rightarrow$ AC & -0.405 & 0.196 & -2.066 & 0.039 \\
Optimism $\rightarrow$ ELE & 1.109 & 0.302 & 3.667 & $p<0.001$ \\
Optimism $\rightarrow$ TM & 1.831 & 0.412 & 4.441 & $p<0.001$ \\
Insecurity $\rightarrow$ TM & -0.109 & 0.206 & -0.529 & 0.597 \\
Insecurity $\rightarrow$ ELE & -0.235 & 0.162 & -1.450 & 0.147 \\
Insecurity $\rightarrow$ AC & 0.006 & 0.213 & 0.030 & 0.976 \\
\hline
\end{tabular}


Table 4. TRI factors: Means of intercepts.

\begin{tabular}{lcccc}
\hline & Optimism & Discomfort & Innovativeness & Insecurity \\
\hline \multicolumn{4}{l}{ Females compared to males } \\
Estimate & -0.193 & 0.204 & -1.016 & 0.332 \\
S.E. & 0.08 & 0.179 & 0.155 & 0.117 \\
C.R. & -2.408 & 1.137 & -6.57 & 2.839 \\
$p$ & 0.016 & 0.256 & $<0.001$ & 0.005 \\
18-39 Years & olds compared to $40-50$ & years old respondents & \\
Estimate & 0.104 & -0.023 & 0.264 & -0.378 \\
S.E. & 0.079 & 0.177 & 0.155 & 0.117 \\
C.R. & 1.316 & -0.129 & 1.703 & -3.22 \\
$p$ & 0.188 & 0.897 & 0.089 & 0.001 \\
\hline
\end{tabular}

Table 5. Attitude objects: Means of intercepts.

\begin{tabular}{|c|c|c|c|}
\hline & $\mathrm{TM}$ & $\mathrm{AC}$ & ELE \\
\hline \multicolumn{4}{|c|}{ Females compared to males } \\
\hline Estimate & -0.405 & -0.931 & -0.099 \\
\hline $\mathrm{SE}$ & 0.286 & 0.291 & 0.216 \\
\hline $\mathrm{CR}$ & -1.418 & -3.197 & -0.456 \\
\hline$P$ & 0.156 & 0.001 & 0.649 \\
\hline \multicolumn{4}{|c|}{ 18-39-year old compared to 40-50-year old respondent } \\
\hline Estimate & 0.848 & -0.059 & -0.229 \\
\hline $\mathrm{SE}$ & 0.266 & 0.29 & 0.216 \\
\hline $\mathrm{CR}$ & 3.188 & -0.205 & -1.063 \\
\hline$P$ & 0.001 & 0.838 & 0.288 \\
\hline
\end{tabular}

personal choice or choice for a relative) and was set to covary. This baseline model had acceptable fit $\left(\chi^{2}=183.67, d f=25, p<0.001, \chi^{2} / d f=7.35\right)$. A CFI 0.933, $\mathrm{NFI}=0.923, \mathrm{IFI}=0.93, \mathrm{TLI}=0.90$, and RMSEA $=0.14)$ although the parsimony adjusted index provided less robust results.

Then again Multiple-Group Analysis was run for evaluating subgroup differences. Intercepts and regression weights were unequal between the measurement models in both the analyses. Comparison of this model with the two original baseline models yielded significant difference. In case of gender, it was $\Delta \chi^{2}=12.94$, $\Delta d f=3, p=0.005$ and age $\Delta \chi^{2}=15.40, \Delta d f=3, p=0.002$. Evaluation of the three attitude objects differs significantly among groups based on gender $\left(\chi^{2}=12.94\right.$, $p=0.005)$ and age $\left(\chi^{2}=15.60, p<0.001\right)$. According to Multiple-Group Analysis, females tend to hold less favorable attitudes toward AC $(p<0.001)$ and $40-50$ yearold respondents consider TM more advantageous than younger respondents (Table 5).

\section{Discussion}

Readiness to new technologies had been studied with regard to several hightech solutions. Such as mobile commerce [Joo (2015)] and online shopping [Roumeliotis and Maria (2014)], voting on parliamentary elections [Rojas-Méndez and 
Parasuraman (2015)], diagnosing medical problems [Rojas-Méndez and Parasuraman (2015); Ramtohul (2015)] and in more cases technology readiness was studied related to a specific software [Walczuch et al. (2007)]. Although people necessarily have to get accommodated to new technologies from day to day, little is known about their overall willingness to adopt technological innovations, thus predicting this would be indispensable from both the side of the users as well as the providers. This study offers a new perspective, by investigating general attitudes toward technologies expected to become widespread in the near future. Additional technologies were chosen which can have decisive influence on different fields of our everyday life.

The research drew upon the concept of Parasuraman [2000] and used the TR construct to capture people's capacity to adopt technologies because it can be used to examine people's attitudes toward technologies of which they have not yet had personal experiences.

\subsection{The fundamental role of technological optimism}

It can be asserted that as in other studies in different countries [e.g. Øyen et al. (2017); Cai et al. (2017)], Hungarian respondents generally hold positive attitudes toward technology. As it was expected, driver factors of the TRI (i.e. optimism and innovativeness) had negative relationships with inhibiting factors (discomfort and insecurity) and had positive relationship with favorable attitudes toward the three technological solutions. However, in the SEM analyses it was solely technological optimism that consistently showed the strongest and significant predictive power. This may be because it contained generally expressed items in particular with respect to everyday usage (e.g.: "Technology gives people more control over their daily lives."). Another possible explanation is that optimism served as a mediator between technological solutions and other TRI attitudes. Lower level of insecurity concerns, feeling competent and confident when using technology may compose the background of technological optimism and may induce a higher level of it. Some previous research also noted that optimism was one of the most important components of the technology readiness. For example, in the investigation of Walczuch et al. [2007], optimism strongly predicted employee's perceived usefulness and ease-of-use of some IT technologies that is why they focused on the negative effects to a lesser extent. Another study conducted by Liljander et al. [2006] also highlights the role of optimism as it was most strongly associated with willingness to use some self-service and Internet check-in technologies, while other TRI dimensions had only a marginal effect. The present study is noteworthy in the way that these investigations came to similar conclusions studying specific softwares and services actually used by the consumer, in this case it could be expected implicitly that innovativeness would have stronger effect as future technologies were taken into consideration in the present study.

\subsection{The unique significance of discomfort in case of Telemedicine}

Feelings of discomfort seem to be specific only in the case of TM. Knowing that when potential risk factors are present, technological attitudes become conspicuous 
[Rojas-Méndez and Parasuraman (2015)]. It may be that in case of TM when health comes into view, an error can be more fraught with risk. This is illustrated by the written notes and comments given by respondents after the estimations of technologies. These explanations mainly emphasize concerns of impredictability of the devices and the marginalization of the doctor-patient realtionship, e.g. "Meeting the doctor gives me the calming feeling of security." This sheds light on the significance of giving sufficient information to patients and careful handling of the data when putting TM into everyday healthcare practice [Gajanayake et al. (2016); Ivanov et al. (2015); Ramtohul (2015)].

\subsection{The role of sociodemographic characteristics}

According to the results, there are significant gender differences according to the TRI factors. It can be concluded that generally females hold less advantageous technology attitudes than males as it was expected [Cai et al. (2017); Venkatesh and Morris (2000)]. But when evaluating concrete technological solutions, it was only supported in the case of AC preferred by males. The reason for that could be gender difference in some fields of interest [Billington et al. (2007)] or that males are more aware of the benefits of an AC, and possibly they regard themselves more proficient utilizing it [Cai et al. (2017)].

Age also seemed to have an important impact on technological attitudes, but only in the case when insecurity reached the level of statistical significance. This is in line with previous studies and it can be assumed that younger age groups are more confident and regard themselves much competent at using technology in general [RojasMéndez and Parasuraman (2015); Rojas-Méndez et al. (2017); Yol et al. (2006); Siren and Knudsen (2017)]. In case of TM, age also played a significant role, however this opportunity was regarded the most beneficial according to older participants (40-50 year olds). On first viewing this is in contrast with the general assumption that younger people are more open to new technologies [Rojas-Méndez and Parasuraman (2015); Yol et al. (2006); Rojas-Méndez et al. (2017); Siren and Knudsen (2017)]. However, considering that in advancing years, health problems become more common, when people experience declining health they visit the doctor more often [Hunt et al. (1981)]. This way the tendency to adopt a technology which can bridge distances can be a prosperous possibility for residents of isolated areas. On the other hand, it can be that as they are less familiar with the use of info-communication techniques, they also take into account the possible risks to a lesser extent [Sucala et al. (2017)].

\subsection{Limitations}

Technology readiness is a widely used theoretical construct and was applied as a short version of the TRI relying upon a previous Hungarian study. However, structural equation models raised some concerns about the factor structure and the applicability of the TRI construct on the Hungarian sample as only optimism proved to have significant impact. This implies further investigations concerning psychometric properties of the Hungarian version of the TRI [Martos et al. (2019)] further examining it on an extended sample and involving other measurements of similar constructs. 
Although most previous studies have pointed out that technology readiness [Parasuraman (2000)] and actual use of technology-based services are interrelated [Parasuraman (2000); Rojas-Méndez and Parasuraman (2015)], no causal relationships can be derived from the present research design, which was cross-sectional and correlational. The interpretability of the results was also narrowed by some characteristics of our sample as it was biased by more women taking part and most of the participants having higher education level. In any subsequent follow-up study, it would be important to involve respondents with only a primary level of education as according to several studies education level is directly proportional to technology use behavior [Rojas-Méndez and Parasuraman (2015); Magotra et al. (2015)]. Finally, respondents completed the test battery via the Internet and in this way participants who actually use this modern technology and conceivably had an indigenous openness to new technologies were reached. Nonetheless, in using this approach, it was possible to reach a significant number of respondents. Additionally, considering the statistics of the households owning info-communication technologies and characteristics of personal use, it can be seen that from 2005 to 2014 the ratio of households with broadband access increased from $10.9 \%$ to $72.4 \%$ [KSH (2014)] and in 2016 almost $90 \%$ of the population connected to the Internet on a daily basis [KSH (2016)].

\subsection{Future directions}

The present research lays out several new directions for investigation. Because TM and ELE would assist ill, old or disabled individuals, in future research it would be important to measure the attitudes of patients with specific illnesses, and also the attitudes of their relatives. Experts from different areas perceive technology differently [Sucala et al. (2017)], and as such, it would be important to investigate the attitudes of healthcare professionals as potential users.

In the present Hungarian sample, there were specific patterns of technology readiness, i.e. the exceptional role of optimism or the feeling of insecurity towards TM. It would be advisable bringing to light which aspects have the greatest weight when evaluating a technology. For that, exploiting qualitative techniques as in some previous papers [Mick and Fournier (1998); Ramtohul (2015); Siren and Knudsen (2017)] would be recommended also in a Hungarian adult sample.

Aware of the fact that attitudes are strong predictors of behavior under certain circumstances [Ajzen (1991)], this study has implications for practice that should be kept in mind by health care and other service providers when they aim to ease the consumer's adaptation to new technologies that are emerging every day [Mesko (2015); Meskó et al. (2017)].

\section{References}

Ajzen, I. (1991). The theory of planned behavior. Organizational Behavior and Human Decision Processes, 50, 2: 179-211.

Al Dahdah, M., Du Loû, A. D. and Méadel, C. (2015). Mobile health and maternal care: A winning combination for healthcare in the developing world? Health Policy and Technology, 4, 3: 225-231. 
Batra, U., Sachdeva, S. and Mukherjee, S. (2015). Implementing healthcare interoperability utilizing SOA and data interchange agent. Health Policy and Technology, 4, 3: 241-255.

Billington, J., Baron-Cohen, S. and Wheelwright, S. (2007). Cognitive style predicts entry into physical sciences and humanities: Questionnaire and performance tests of empathy and systemizing. Learning and Individual Differences, 17, 3: 260-268.

Bosch (2016). Sajtóközlemény: Ismét átfogó képet nyújt a magyar autóhasználati szokásokról a Bosch kutatása (Press release: Bosch's Research Gives a Comprehensive View of Hungarian Vehicle Usage Behaviour.). Available at: http://www.boschmediaservice.hu/files/press_ data/press_documents/Sajtokozlemeny_2016-05-10_4200.pdf - downloaded: 2018.03.17 [accessed on 20 May 2016].

Cai, Z., Fan, X. and Du, J. (2017). Gender and attitudes toward technology use: A metaanalysis. Computers \& Education, 105, 1: 1-13.

Chen, M. F. and Lin, N. P. (2018). Incorporation of health consciousness into the technology readiness and acceptance model to predict app download and usage intentions. Internet Research, 28, 2: 351-373.

Danis, J., Forczek, E. and Bari, F. (2016). A telemedicina alkalmazása a bőrgyógyászatban: A teledermatológia (Using telemedicine in dermatology: Teledermatology). Orvosi Hetilap, 157, 10: 363-369.

Do, Q., Martini, B. and Choo, K. K. R. (2016). Is the data on your wearable device secure? An android wear smartwatch case study. Software: Practice and Experience, 47, 3: 391-403.

Dobre et al. (ed.) (2016). Ambient Assisted Living and Enhanced Living Environments: Principles, Technologies and Control. Butterworth-Heinemann.

eNet (2017). 5G: 10-ből 5 netezö használná (5G: 5 from 10 Internet user would use it). Available at: http://www.enet.hu/hirek/5g-tizbol-het-netezo-hasznalna/downloaded [accessed on 25 May 2018].

Fayers, P. M. and Sprangers, M. A. (2002). Understanding self-rated health. The Lancet, 359, 9302: $187-188$.

Gajanayake, R., Iannella, R. and Sahama, T. (2016). An insight into the adoption of accountable-eHealth Systems-an empirical research model based on the Australian context. IRBM, 37, 4: 219-231.

Garcia, E. and Herrero, J. (2009). Internet use and self-rated health among older people: A national survey. Journal of Medical Internet Research, 11, 4: e49.

Gell et al. (2013). Patterns of technology use among older adults with and without disabilities. The Gerontologist, 55, 3: 412-421.

Glinkowski, W. (2006). Telemedicine and eHealth. In Proceedings of the XI International Conference Medical Informatics 83 Technologies, eds. E. Piętka, J. Lęski and S. Franiel, Medical Informatics \& Technologies, https://itib.polsl.pl/mit/papers/I-23.pdf, 2019.07.23.

Huang et al. (2017). Development of a smart wheelchair with dual functions: Real-time control and automated guide. In 2017 2nd IEEE International Conference on Control and Robotics Engineering (ICCRE) (pp. 73-76). April 2017, Bangkok, Thailand.

Hunt et al. (1981). The Nottingham Health Profile: Subjective health status and medical consultations. Social Science \& Medicine. Part A: Medical Psychology 83 Medical Sociology, 15, 3: 221-229.

Ivanov, A., Sharman, R. and Rao, H. R. (2015). Exploring factors impacting sharing healthtracking records. Health Policy and Technology, 4, 3: 263-276.

Joo, J. H. (2015). Understanding Korean college students social commerce behavior through an integrated model of technology readiness, technology acceptance model, and theory of planned behavior. Journal of Digital Convergence, 13, 7: 99-107.

Kapiriri, L. (2015). Ethical challenges in clinical decision-making in the era of new technologies: Experiences from low income countries. Health Policy and Technology, 4, 3: 256-262.

Kerschner, C. and Ehlers, M. H. (2016). A framework of attitudes towards technology in theory and practice. Ecological Economics, 126, 139-151. 
Király, Gy. and MAIN Csoport (2010). Az e-Egészségügy (e-Health) helyzete Magyarországon. (Situation of e-Health in Hungary.), IME, 9(2), 45-48.

Kliem, A. et al. (2016). A reconfigurable middleware for on-demand integration of medical devices. IRBM, 37, 4: 198-209.

Krishna et al. (2016). Computer aided abnormality detection for kidney on FPGA based IoT enabled portable ultrasound imaging system. IRBM, 37, 4: 189-197.

KSH. (2014). Statistics — households owning info-communication technologies and characteristics of personal use. Available at: https://www.ksh.hu/docs/hun/xstadat/xstadat_ eves/i_oni006.html - downloaded [accessed on 19 March 2018].

KSH (2016). Statistics — prevalence of internet use. Available at: https://www.ksh.hu/docs/ hun/xstadat/xstadat_eves/i_oni017.html - downloaded [accessed on 19 March 2018].

Kwon, H., Kim, J. and Park, Y. (2017). Applying LSA text mining technique in envisioning social impacts of emerging technologies: The case of drone technology. Technovation, $\mathbf{6 0}$, $15-28$.

Larburu et al. (2016). Quality-of-data broker for quality-of-data-aware telemedicine systems. IRBM, 37, 4: 210-218.

Liljander et al. (2006). Technology readiness and the evaluation and adoption of self-service technologies. Journal of Retailing and Consumer Services, 13, 3: 177-191.

Magotra, I., Sharma, J. and Sharma, S. K. (2015). Technology adoption propensity of the banking customers in India: An insight. International Journal of Management, Accounting and Economics, 2, 2: 111-124.

Marçal, R. et al. (2017). AUTONOMOUS VEHICLES: Scientometric and bibliometric studies. In 25th International Colloquium of Gerpisa-R/Evolutions. New Technologies and Services in the Automotive Industry, June 2017, Paris, France, ffhal-01652939.

Martens, M., Roll, O. and Elliott, R. (2017). Testing the technology readiness and acceptance model for mobile mayments across Germany and South Africa. International Journal of Innovation and Technology Management, 14, 6: 1750033.

Martos, T. et al. (2019). A technológiai megoldásokkal kapcsolatos attitűdök mérése: a TRI és a TAP magyar változatának pszichometriai jellemzői. Alkalmazott Pszichológia, 19, 1 (in press). (Assesment of attitudes toward technological solutions: Psychometric properties of the Hungarian versions of TRI and TAP.)

Mesko, B. (2015). Commentary: We need to be better prepared for a technological future. BMJ (Clinical research ed.), 350, 279.

Meskó, B. et al. (2017). Digital health is a cultural transformation of traditional healthcare. mHealth Journal, 3(9). Published online 2017 September 14, doi: 10.21037/mhealth. 2017.08.07.

Mick, D. G. and Fournier, S. (1998). Paradoxes of technology: Consumer cognizance, emotions, and coping strategies. Journal of Consumer Research, 25, 2: 123-143.

Mrosek, R., Dehling, T. and Sunyaev, A. (2015). Taxonomy of health IT and medication adherence. Health Policy and Technology, 4, 3: 215-224.

Orbók, Á. (2015). Az autonóm közlekedési technológia kihívásai. (Challenges of the autonomous vehicular technology), Társadalom és honvédelem, 19, 1: 221-226.

Øyen K. R. et al. (2017). Understanding attitudes toward information and communication technology in home-care: Information and communication technology as a market good within Norwegian welfare services. Informatics for Health and Social Care, 43, 3: 300-309. DOI: $10.1080 / 17538157.2017 .1297814$.

Parasuraman, A. (2000). Technology Readiness Index (TRI) a multiple-item scale to measure readiness to embrace new technologies. Journal of Service Research, 2, 4: 307-320.

Ramtohul, I. (2015). The adoption of e-health services: Comprehensive analysis of the adoption setting from the user's perspective. Health Policy and Technology, 4, 3: 286-293.

Riquelme, H. E. and Rios, R. E. (2010). The moderating effect of gender in the adoption of mobile banking. International Journal of Bank Marketing, 28, 5: 328-341. 
Rojas-Méndez, J. I. and Parasuraman, A. (2015). Consumers' readiness to accept technologybased products and services in developing countries: The Chilean experience. Multidisciplinary Business Review, 8, 1: 14-24.

Rojas-Méndez, J. I., Parasuraman, A. and Papadopoulos, N. (2017). Demographics, attitudes, and technology readiness: A cross-cultural analysis and model validation. Marketing Intelligence $\&$ Planning, 35, 1: 18-39.

Roumeliotis, M. and Maria, T. (2014). Perception and adoption of technology based services by students of higher education. International Journal of Scientific and Research Publications, 4, 3: 1-5.

Schreiber, J. B., Nora, A., Stage, F. K., Barlow, E. A. and King, J. (2006). Reporting structural equation modeling and confirmatory factor analysis results: A review. The Journal of Educational Research, 99, 6: 323-338.

Siren, A. and Knudsen, S. G. (2017). Older adults and emerging digital service delivery: A mixed methods study on information and communications technology use, skills, and attitudes. Journal of Aging \& Social Policy, 29, 1: 35-50.

Smith, M., Walford, N. S. and Jimenez-Bescos, C. (2018). Assessing the user response to differences in functionality when visualising $3 \mathrm{D}$ models of cultural heritage sites using the Technology Readiness Index. Digital Applications in Archaeology and Cultural Heritage, 10, 6: 1-23. DOI: https://doi.org/10.1016/j.daach.2018.e00076.

Sucala, M., Nilsen, W. and Muench, F. (2017). Building partnerships: A pilot study of stakeholders' attitudes on technology disruption in behavioral health delivery and research. Translational Behavioral Medicine, 7, 4: 854-860.

Sun, W., Liu, J. and Zhang, H. (2017). When smart wearables meet intelligent vehicles: Challenges and future directions. IEEE Wireless Communications, 24, 3: 58-65.

Swan, M. (2015). Connected car: Quantified self becomes quantified car. Journal of Sensor and Actuator Networks, 4, 1: 2-29.

Tsikriktsis, N. (2004). A technology readiness-based taxonomy of customers: A replication and extension. Journal of Service Research, 7, 1: 42-52.

Venkatesh, V. and Morris, M. G. (2000). Why don't men ever stop to ask for directions? Gender, social influence, and their role in technology acceptance and usage behavior. MIS Quarterly, 24, 1: 115-139.

Wahlster, P., Scahill, S. and Lu, C. Y. (2015). Barriers to access and use of high cost medicines: A review. Health Policy and Technology, 4, 3: 191-214.

Walczuch, R., Lemmink, J. and Streukens, S. (2007). The effect of service employees' technology readiness on technology acceptance. Information $\mathcal{E}$ Management, 44, 2: 206-215.

Wang, Y. S., Wu, M. C. and Wang, H. Y. (2009). Investigating the determinants and age and gender differences in the acceptance of mobile learning. British Journal of Educational Technology, 40, 1: 92-118.

WHO (2017). Process of translation and adaptation of instruments: World Health Organization - downloaded. Available at: http://www.who.int/substance_abuse/research_ tools/translation/en/ [accessed on 2 April 2017].

Webcache. (2017). Digital in 2017: Global Overview - downloaded. Available at: https:// webcache.googleusercontent.com/search? $\mathrm{q}=$ cache:kD7x9iHyiFAJ:https://wearesocial. $\mathrm{com} /$ special-reports/digital-in-2017-global-overview $+\& \mathrm{~cd}=3 \& \mathrm{hl}=\mathrm{hu} \& \mathrm{ct}=\mathrm{clnk} \& \mathrm{gl}=\mathrm{hu}$ [accessed on 22 May 2018].

Yol, S., Serenko, A. and Turel, O. (2006). Moderating roles of user demographics in the American customer satisfaction model within the context of mobile services. Journal of Information Technology Management, 17, 4: 20-32.

Zhang, Y., Yi, J. and Liu, T. (2013). Embedded flexible force sensor for in-situ tire-road interaction measurements. IEEE Sensors Journal, 13, 5: 1756-1765.

Zhou, L., Dai, L. and Zhang, D. (2007). Online Shopping Acceptance Model-A critical survey of consumer factors in online shopping. Journal of Electronic Commerce Research, 8, 1: $41-62$. 


\title{
Appendix A. Technology Readiness Index (Shortened Version)
}

\author{
Innovativeness
}

- Other people come to you for advice on new technologies

- You find you have fewer problems than other people in making technology work for you

- You enjoy the challenge of figuring out high-tech gadgets

Insecurity

- You do not consider it safe giving out a credit card number over a computer

- You do not consider it safe to do any kind of financial business online

- Any business transaction you do electronically should be confirmed later with something in writing

Optimism

- Technology gives you more freedom of mobility

- Technology makes you more efficient in your occupation

- Technology gives people more control over their daily lives

Discomfort

- Many new technologies have health or safety risks that are not discovered until after people have used them

- There should be caution in replacing important people-tasks with technology because new technology can breakdown or get disconnected

\section{Biography}

Sára Imola Csuka is psychologist, currently a doctoral student at Károly Rácz School of PhD Studies, Semmelweis University and an assistant lecturer at Bárczi Gusztáv Faculty of Special Needs Education, Eötvös Loránd University, Budapest, Hungary. Her research interests include psychological aspects of chronic illnesses, social support, motivation of health behaviour and the applicability of technology in healthcare domain.

Tamás Martos Ph.D., is a health psychologist and associate professor at the Institute of Psychology, University of Szeged, Hungary. His research interests include the role of motivational processes and goal constructs in healthy human functioning, positive psychology as well as psychological aspects of technology use.

Mihály Kapornaky MA., is a social psychologist, currently a research assistant at the Department of Social Psychology, Eötvös Loránd University, Budapest, Hungary. His research interests include the application of Big Data methodology in social sciences, and the social psychology of social media and technology, especially the predictive power of online emotional reactions. 
Viola Sallay Ph.D., is a health psychologist and assistant professor at the Institute of Psychology, University of Szeged, Hungary. Her research interests include emotional self-regulation processes in the physical environment as well as the role of technology in close relationships.

Christopher Alan Lewis is based in the Department of Social and Behavioural Sciences, Leeds Trinity University, UK. He is a Health Psychologist, with particular interests in culture, mental health, and religion. 